\title{
The tuberculosis time bomb: taking control of the TB threat in Europe
}

\author{
Tanja El-Nemr
}

Affiliations: European Respiratory Society, Brussels, Belgium.

Correspondence: T. El-Nemr, European Respiratory Society, 49-51 rue de Trèves, Brussels 1040, Belgium. E-mail: ersinfo.brusselsdersnet.org

@ERSpublications

MDR-TB: the ERS calls for more EU funding for TB research and more political incentives to invest in TB drug development http://ow.ly/t1Ggv

\section{Context}

Tuberculosis (TB) has been described as the biggest killer in human history. Mycobacterium tuberculosis emerged over 70000 years ago, and it has shared evolutionary paths with modern humans since their early migration out of Africa [1]. With the expansion of human populations and the emergence and change of livelihoods and lifestyles, M. tuberculosis evolved and diversified, and continues to do so today.

The prognosis of TB patients before the advent of the antibiotic era was very bleak. In the 1900s, exacerbated by poor hygiene and housing conditions, TB was killing one out of every seven people in Europe and Americas [2]. In cities, it caused $40 \%$ of working class deaths.

The identification of the tuberculosis bacillus in 1882 by Robert Koch represented a turning point that would be followed by the development of public health practices, vaccines and, in the 1940s and 1950s, antibiotics [3]. This led to the more effective treatment of TB, raising hopes that the disease would be defeated: the United Nations predicted the elimination of TB by the year 2025 [4]. Unfortunately, it seems now that we are coming close to the end of the antibiotic era. New strains of multidrug-resistant (MDR)-TB started to appear in the mid-1980s in some developed countries [5, 6], and, by 1993, the World Health Organization (WHO) had declared TB a global public health emergency [7]. The WHO currently estimates that one third of the world's population is infected with TB [8] and, in Europe, TB kills 7 people every hour [9].

\section{What is the European Respiratory Society doing?}

The European Respiratory Society (ERS) has been engaged in TB control since its foundation in 1990, and works closely with the WHO, the European Centre for Disease Prevention and Control and other relevant bodies and organisations [10-12]. Over the past 15 years, the ERS has offered more than 30 symposia and 120 presentations on TB control and related public health aspects to thousands of respiratory specialists from all over the world, through the ERS conferences.

The ERS has launched numerous actions on TB control and elimination. The latest one of these, the ERS/ WHO consilium [13-15], which commenced in April 2013, is a very important global initiative to improve clinical management of difficult-to-treat TB cases or micro-epidemics. This free, web-based platform allows physicians who deal with complex multi- or extensively drug-resistant TB, TB/HIV and other TB cases to receive full personalised written treatment advice from two experts within a few days.

\section{What needs to be advocated?}

The circumstances in which multidrug resistance is allowed to develop must be addressed, and this requires political will. TB used to be characterised as a disease of poverty, and this remains the case today. The 18th

Received: Jan 102014 | Accepted after revision: Jan 262014

Conflict of interest: T. El-Nemr is an employee of the European Respiratory Society. 

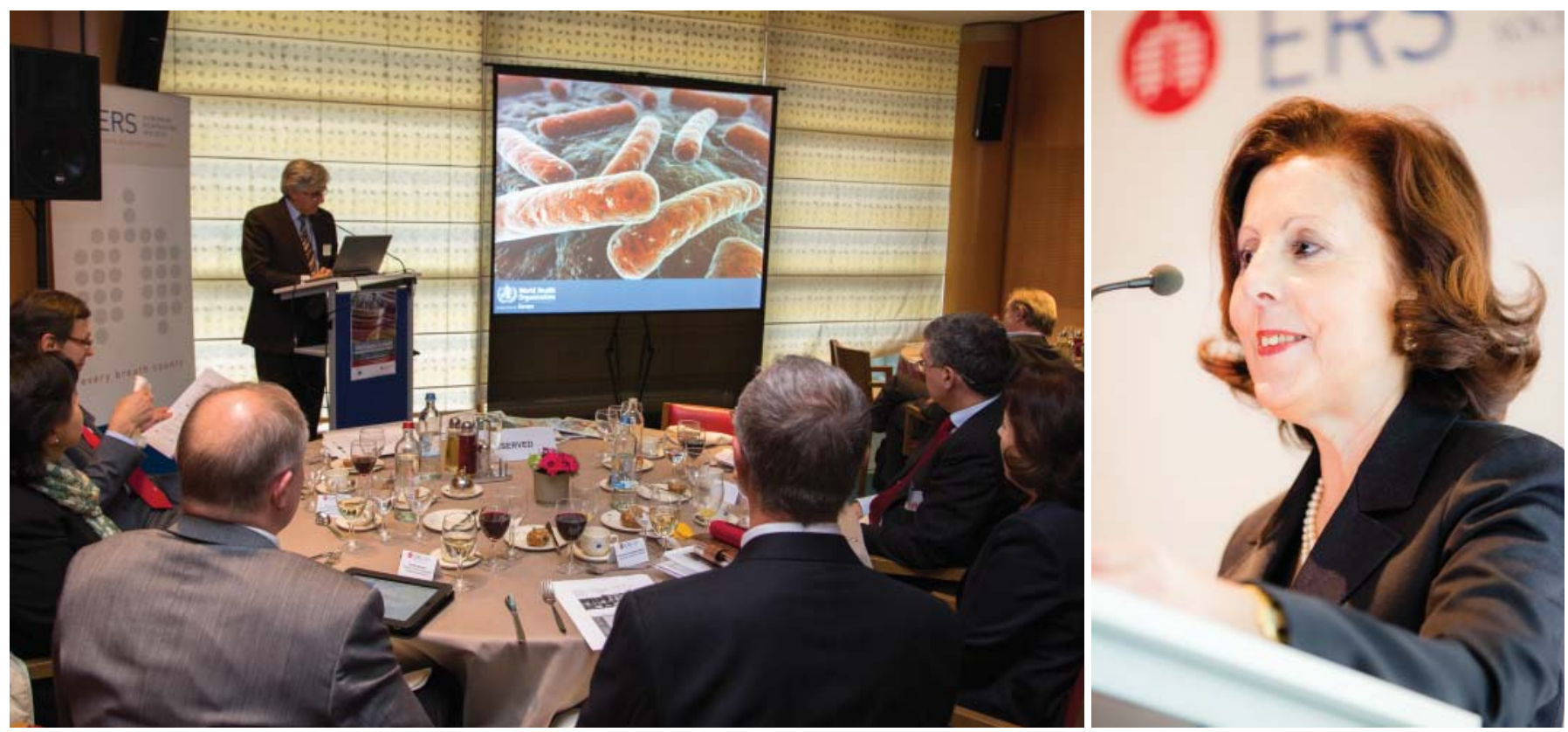

FIGURE 1 The European Respiratory Society hosted an event on tuberculosis (TB) awareness on November 13, 2013. One of the key messages delivered at this event was that, despite the dire situation, TB elimination in Europe is possible. The TB awareness event was hosted by MEP, Prof. Maria Da Graça Carvalho (right).

century descriptions of cramped houses in cities bear similarities to the news stories media in Europe are reporting today about outbreaks of TB and the conditions surrounding the patients. While anyone can contract $\mathrm{TB}$, the risk increases significantly among the most vulnerable.

This political will needs to be extended to a regional level, and in particular in terms of public health and cross-border healthcare. MDR-TB is rampant in the some countries in the WHO European region, which often lack the resources or willingness to tackle diseases that primarily affect marginalised groups [16, 17]. To counteract the development of MDR-TB and its spread, public health funding must be made available in these countries, regions and cities.

According to a conservative estimate, the European Union currently spends at least 5.3 billion euros on TB annually [18]. Instead of continuing on this path, we need to focus on prevention in order to get sustainable results. More European funding is required for research and development of new diagnostics, drugs and vaccines. It is imperative that governments create incentives for researchers, clinics and the industry to invest more in the development of antibiotics. Few new antibiotics have come on-stream and many companies are even pulling out of antibiotic drug development as a result of poor return on investment [19-23].

These are some of the issues that were addressed in a recent ERS event, organised in the European Parliament in November 2013. This event was hosted by MEP Maria Da Graça Carvalho, and it brought together leading European TB experts, MEPs and representatives of non-government organisations, pharmaceutical companies and the European Commission (fig. 1). In this successful event, the ERS also launched its key messages on TB control, calling for clear targets and plans for TB control and elimination [24, 25].

The ERS is committed to political TB advocacy. In view of the World TB day on March 24 [2], and as a follow-up to the event in November, the ERS will organise a second event with MEP Carvalho on April 1 in the European Parliament. For the past 5 years the ERS has been responsible for the dissemination Work Package within the TB-PANNET project [26], a major FP7-funded TB research project aimed at fighting MDR-TB. In this particular event, the ERS will share the project outcomes and advocate further action on $\mathrm{TB}$ at the political level.

\section{References}

Comas I, Coscolla M, Luo T, et al. Out-of-Africa migration and neolithic coexpansion of Mycobacterium tuberculosis with modern humans. Nature Genet 2013; 45: 1176-1182.

2 Stop TB Partnership. World TB Day. www.stoptb.org/events/world_tb_day January 10, 2014. Date last accessed: January 10, 2014.

Migliori GB, Sotgiu G, Lange C, et al. Extensively drug-resistant tuberculosis: back to the future. Eur Respir J 2010; 36: $475-477$. 
National Institute of Allergy and Infectious Diseases. Tuberculosis. www.niaid.nih.gov/topics/tuberculosis/ understanding/history/pages/historical_optimism.aspx August 12, 2010. Date last accessed: January 10, 2014.

5 Falzon D, Gandhi N, Migliori GB, et al. Resistance to fluoroquinolones and second-line injectable drugs: impact on MDR-TB outcomes. Eur Respir J 2013; 42: 156-168.

6 Migliori GB, Sotgiu G, Gandhi NR, et al. Drug resistance beyond extensively drug resistant tuberculosis: individual patient data meta-analysis. Eur Respir J 2013; 42: 169-179.

$7 \quad$ Glaziou P, Floyd K, Korenromp EL, et al. Lives saved by tuberculosis control and prospects for achieving the 2015 global target for reducing tuberculosis mortality. Bull World Health Organ 2011; 89: 573-582.

8 Diel R, Loddenkemper R, Zellweger JP, et al. European Forum for TB Innovation. Old ideas to innovate tuberculosis control: preventive treatment to achieve elimination. Eur Respir J 2013; 42: 785-801.

9 World Health Organization. Tuberculosis. www.euro.who.int/en/health-topics/communicable-diseases/tuberculosis/ tuberculosis Updated 2014. Date last accessed: January 10, 2014.

10 Blasi F, Barnes PJ, Gaga M, et al. Future directions for the ERS: presidential plans. Eur Respir J 2013; 42: 875-880.

11 Migliori GB, Zellweger JP, Abubakar I, et al. European Union standards for tuberculosis care. Eur Respir J 2012; 39: 807-819.

12 Migliori GB, Sotgiu G, Blasi F, et al. Towards the development of EU/EEA Standards for Tuberculosis Care (ESTC). Eur Respir J 2011; 38: 493-495.

13 Blasi F, Dara M, van der Werf MJ, et al. Supporting TB clinicians managing difficult cases: the ERS/WHO Consilium. Eur Respir J 2013; 41: 491-494.

14 D'Ambrosio L, Tadolini M, Dupasquier S, et al. ERS/WHO TB Consilium: reporting of the initial 10 cases. Eur Respir J 2014; 43: 286-289.

15 ERS/WHO TB Consilium. www.tbconsilium.org Updated 2014. Date last accessed: January 10, 2014.

16 Barnes PJ, Blasi F, Ward B, et al. Respiratory diseases in the world: one voice "united for lung health". Eur Respir J 2014; 43: 3-5.

17 Warwick B, Kuehne J, Corazza A, et al. Bridging the Gap. How the European Union Can Address the Funding Crisis for TB and HIV programmes in Eastern Europe and Central Asia. Position Paper. www.action.org/ documents/Bridging_the_Gap_Oct_2013_web_version.pdf October 2013. Date last accessed: January 10, 2014.

18 Diel R, Vandeputte J, de Vries G, et al. Costs of tuberculosis disease in the EU - a systematic analysis and cost calculation. Eur Respir J 2014; 43: 554-565.

19 Skripconoka V, Danilovits M, Pehme L, et al. Delamanid improves outcomes and reduces mortality in multidrugresistant tuberculosis. Eur Respir J 2013; 41: 1393-1400.

20 Tiberi S, De Lorenzo S, Centis R, et al. Bedaquiline in MDR-/XDR-TB cases: first experience on compassionate use. Eur Respir J 2014; 43: 289-292.

21 Gler MT, Skripconoka V, Sanchez-Garavito E, et al. Delamanid for multidrug-resistant pulmonary tuberculosis. N Engl J Med 2012; 366: 2151-2160.

22 Diacon AH, Dawson R, von Groote-Bidlingmaier F, et al. 14-day bactericidal activity of PA-824, bedaquiline, pyrazinamide, and moxifloxacin combinations: a randomised trial. Lancet 2012; 380: 986-993.

23 Braine T. Race against time to develop new antibiotics. Bull World Health Organ 2011; 89: 88-89.

24 D'Ambrosio L, Dara M, Tadolini M, et al. TB Elimination: theory and practice in Europe. Eur Respir J 2014 [In press DOI: 10.1183/09031936.00198813].

25 European Respiratory Society. Tuberculosis in Europe. ERS Key Messages. www.ersnet.org/images/stories/EUaffairs/ers\%20key\%20messages.pdf November 7, 2013. Date last accessed: January 10, 2014.

26 TB PAN NET. European Network for Study and Clinical Management of TB Drug Resistance. www.tbpannet.org September 7, 2013. Date last accessed: 10 January, 2014. 